\title{
BMJ Open Patient safety in ambulatory care from the patient's perspective: a retrospective, representative telephone survey
}

\author{
Max Geraedts (D) , ${ }^{1}$ Svenja Krause, ${ }^{1}$ Michael Schneider, ${ }^{1}$ Annette Ortwein, ${ }^{1}$ \\ Johannes Leinert, ${ }^{2}$ Werner de Cruppé ${ }^{1}$
}

To cite: Geraedts M, Krause S, Schneider M, et al. Patient safety in ambulatory care from the patient's perspective: a retrospective, representative telephone survey. BMJ Open 2020;10:e034617. doi:10.1136/ bmjopen-2019-034617

- Prepublication history and additional material for this paper are available online. To view these files, please visit the journal online (http://dx.doi. org/10.1136/bmjopen-2019034617).

$M G$ and SK contributed equally.

Received 08 October 2019

Revised 24 January 2020

Accepted 24 January 2020

A Check for updates

(C) Author(s) (or their employer(s)) 2020. Re-use permitted under CC BY-NC. No commercial re-use. See rights and permissions. Published by BMJ.

${ }^{1}$ Institute for Health Services Research and Clinical Epidemiology, PhilippsUniversitat Marburg, Marburg, Germany

${ }^{2}$ infas Institut fur angewandte Sozialwissenschaft GmbH, Bonn, Germany

Correspondence to

Dr Max Geraedts;

geraedts@uni-marburg.de

\section{ABSTRACT}

Objectives Data on patient safety problems (PSPs) in ambulatory care are scarce. The aim of the study was to record the frequency, type, severity and point of origin of PSPs in ambulatory care in Germany.

Design Retrospective cross-sectional study.

Setting Computer-assisted telephone interviews with randomly recruited citizens aged $\geq 40$ years in Germany who were asked about their experiences with PSPs in ambulatory care.

Participants 10037 citizens $\geq 40$ years.

Measures A new questionnaire was developed to record patient experiences with PSPs in ambulatory care. The study reported here targets patient experiences in the last 12 months. The questionnaire focuses on PSPs in seven areas of medical treatment: anamnesis/diagnostic procedures; medication; vaccination, injection, infusion; aftercare; outpatient surgery; office administration; other areas. For each PSP reported, detailed questions were asked about the specialist group concerned, and, on the most serious harm, the severity of the harm and its consequences. The target parameters are presented as proportions with $95 \%$ Cls.

Results 1422 of the respondents (14\%) reported 2589 PSPs. The areas most frequently affected by PSPs were anamnesis/diagnostic procedures $(61 \%)$ and medication (15\%). General practitioners accounted for $44 \%$ of PSPs, orthopaedists for $15 \%$ and internists for $10 \% .75 \%$ of PSPs were associated with harm, especially unnecessarily prolonged pain or deterioration of health; $35 \%$ of PSPs led to permanent harm. 804 PSPs (32\%) prompted patients to see another doctor for additional treatment; 255 PSPs $(10 \%)$ required inpatient treatment.

Conclusion PSPs experienced by patients are widespread in ambulatory care in Germany. The study reveals in which areas of medical treatment efforts to prevent PSPs could make the greatest contribution to improving patient safety. It also demonstrates the valuable contribution of patient reports to the analysis of PSPs.

\section{INTRODUCTION}

Patient safety, as a key feature of quality healthcare, ${ }^{1}$ is the reduction of risk of unnecessary harm associated with healthcare to an acceptable minimum. ${ }^{2}$ Healthcare's growing complexity and an increasing number of multimorbid patients lead to an increasing

\section{Strengths and limitations of this study}

- For the very first time, data were collected on the frequency, type, severity and consequences of patient safety problems (PSPs) in ambulatory care in Germany.

- The randomly selected, extensive population sample of 10037 citizens $\geq 40$ years guarantees a high degree of certainty in the PSP incidence estimates.

- The study provides insights into which PSPs are most likely to cause harm, thus providing a good indication of effective fields of action to improve patient safety.

- Patient reports as a research method for generating data on PSPs without cross-checking against comparative data (eg, medical records) do not allow medical objectification of the reported PSPS.

risk of patient safety problems (PSPs) in both inpatient and ambulatory care. Below we use the term PSP to capture two types of error, that is, failures to carry out a planned action as intended or application of an incorrect plan, and patient safety incidents (PSIs), that is, events or circumstances that could have resulted, or did result, in unnecessary harm to a patient. ${ }^{2}$ PSIs also include adverse events (AEs), that is, incidents which resulted in harm to a patient. ${ }^{2}$

Both internationally and in Germany, knowledge about the frequency of PSPs is limited. Regarding only inpatient care and based on a literature review by the German Coalition for Patient Safety, the German Advisory Council on the Assessment of Developments in the Health Care Sector estimated in 2007 that $5 \%-10 \%$ of all hospital patients experience an $\mathrm{AE}, 2 \%-4 \%$ a preventable $\mathrm{AE}$, $1 \%$ experience treatment errors and $0.1 \%$ die from preventable AEs. ${ }^{3}$ For the German ambulatory care sector, there is hardly any data on the frequency of PSPs. But even the few international studies allow only rough estimates. From the Netherlands, Gaal et $a t^{4}$ report a PSI rate of $21.1 \%$ based on a 
retrospective analysis of medical records kept by primary care physicians; $5.8 \%$ of the PSIs resulted in harm and $0.7 \%$ led to hospital stays. Stocks $e t a \check{l}$ collected potentially harmful preventable problems through personal interviews of a representative sample of $\geq 15$-year-olds in Great Britain; the problem rate within the last 12 months was $7.9 \%$. Michel et at encouraged general practitioners (GPs) in France to record all PSIs occurring within 1 week, and concluded that the PSI rate was $2.6 \%$ of all consultations. In a first review, Sandars and Esmail ${ }^{7}$ estimated the medical error rate in primary care at 5-80 errors per 100 000 consultations. In a recent literature review, Panesar $e t$ $a l^{8}$ concluded that 1-24 PSIs occur per 100 consultations, of which $4 \%$ (range 1\%-44\%) are associated with severe harm.

One reason for this inconclusive evidence could be the process of recording PSPs in ambulatory care, because the methods tested in inpatient care, such as the analysis of medical records, routine and/or harm data, critical incident reporting systems (CIRS) and direct observation, reach their limits. First, patients leave the doctor's surgery immediately after ambulatory treatment, leaving only a short time window for PSP capture, and second, routine data in ambulatory care contain too little information for PSP discovery. The website "every error counts', which collects errors in the German GP sector, illustrates the dilemma of spontaneous PSP reporting in ambulatory care: by mid-2019, that is, during 15 years since the existence of the register, the approximately 55 000 German GPs had reported a total of 948 errors. ${ }^{9}$ For this reason, it is internationally recommended to include patients themselves as sources of information for PSP recording. ${ }^{10-13}$ Only patients are able to report on the effects of treatments across sectors and over long periods of time; their information on incidents is usually more accurate than those of physicians, ${ }^{14}$ who also show more resentment towards PSP reporting. ${ }^{15}$

Against this background, our study aims to report on the frequency, type, severity and point of origin of PSPs in the ambulatory healthcare sector in Germany based on a population survey.

\section{METHODS}

\section{Study design}

This retrospective cross-sectional study is based on original telephone survey data on experiences with PSPs within the last 12 months from the patient's perspective. We followed the Strengthening the Reporting of Observational Studies in Epidemiology checklist for reporting observational studies (see online supplementary file 1). ${ }^{16}$

\section{Participants}

For economic reasons, the survey was limited to the population aged $\geq 40$ years in Germany (2017: 22.5 million men and 24.7 million women; $57 \%$ of the total population), since more physician visits and thus potentially more PSPs are expected for $\geq 40$-year-olds than in the total population.

From the population aged $\geq 40$ years, a sample of 10037 citizens was interviewed via computer-assisted telephone interviews (CATI). This number was based on a sample size calculation of 10000 interviews, with which a twosided $95 \%$ CI of $1 \%$ point can be secured with an estimated incidence of $7.5 \%$. The realised sample was based on a random sample of nationwide listed and permuted landline and mobile phone numbers (70:30 distribution). The target person in multi-person households was the adult with the last birthday. About 81000 of the almost 700000 telephone numbers generated were identified as belonging to the target group; of these, about 65000 were interviewed during field time. $84.4 \%$ refused to participate. Only a few interviews were discontinued (150) or not evaluable (5), thus a participation rate of $12.4 \%$ was achieved $(10037 / 81108)$. The participants in the sample corresponded largely to the population as a whole. In order to be able to make reliable representative statements, the sample results were weighted using the variables gender, age group, household size, school education, employment status, nationality, federal state and municipal size classes.

\section{Survey instrument and implementation}

Due to the absence of a validated CATI survey instrument, a new questionnaire was developed for the study by means of a literature review on types of PSPs in ambulatory care and qualitative interviews with physicians $(n=10)$ and patients $(n=20)$ on their experiences with PSPs. The survey instrument captures PSP experiences within the last 12 months, PSPs since the 40th birthday and severe PSPs of relatives through proxy interviews using closed questions and dichotomous answers. The study reported here targets patients' PSP experiences in the last 12 months. The CATI instrument consists of three modules relating to the last 12 months (see box 1 and online supplementary file 1): (A) introductory questions on the current state of health, and whether the last visit to a GP or specialist took place within the last 12 months. If a physician visit had taken place, a short information text briefly explained the types of PSP collected in the survey. In module (B), individual PSP types were queried in seven medical treatment areas, with multiple answers possible in each case: each person was allowed to report several PSP types if one or several physician visits had taken place in several treatment areas. For each PSP reported, detailed questions were asked about the specialist group concerned and on the most serious harm, the severity of the harm, and its consequences. In order to minimise both, cognitive stress and memory bias, complex filters ensured that the interviewees were just asked the questions relevant to them. Module (C) collected sociodemographic and socioeconomic data.

The questionnaire was checked by means of cognitive pretests on 20 patients with regard to the comprehensibility of the questionnaire items, completeness of 


\section{Box 1 Categories and items of the survey instrument}

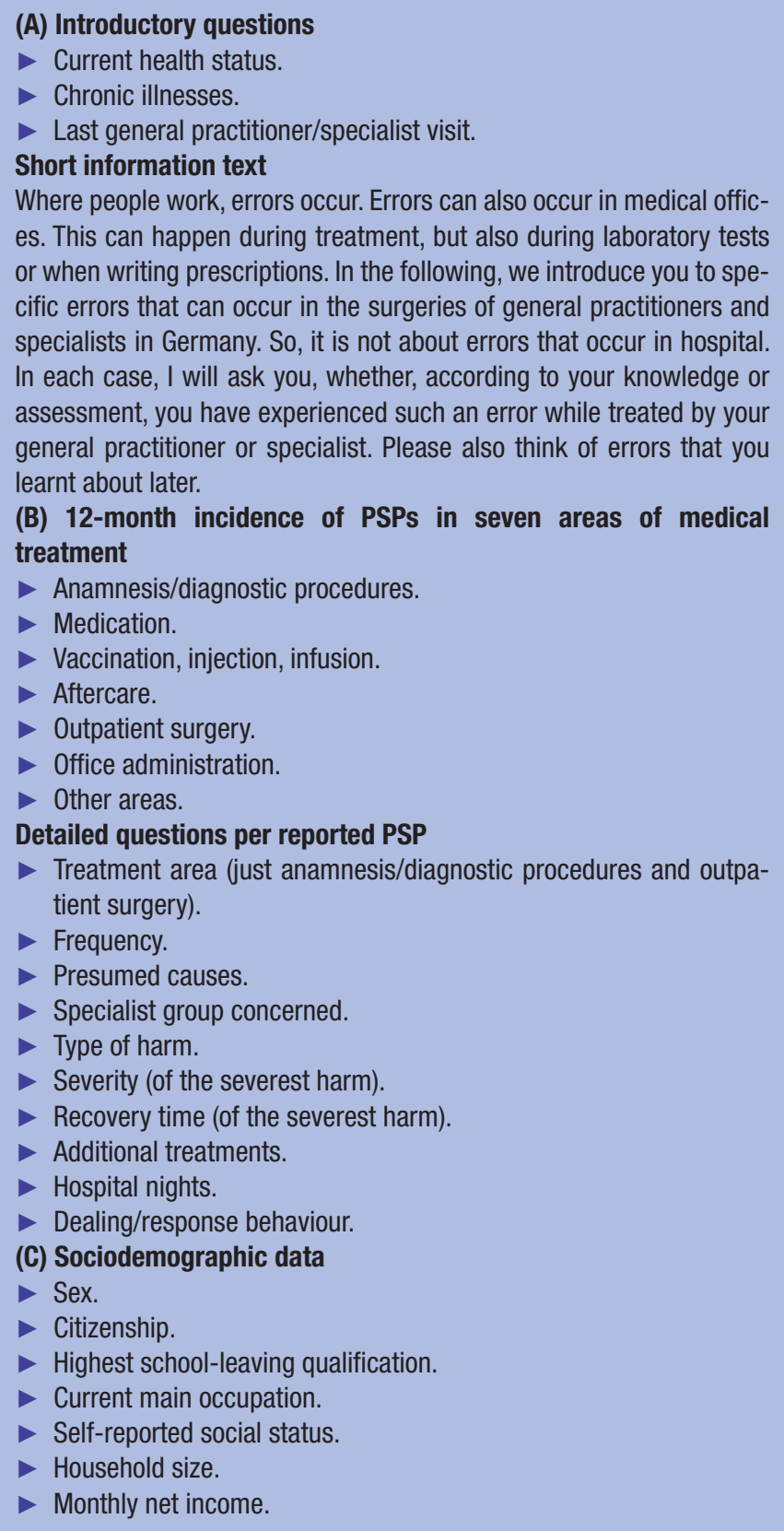

the response categories and memorability of the events experienced. Methodically, think-aloud and interview techniques were combined. ${ }^{17}$ Necessary changes were implemented and subsequently tested using standardised pretests $(\mathrm{n}=110)$ under field conditions. Misleading formulations of questions and optimisation possibilities regarding filtering or question blocks were discovered, modified in the electronic questionnaire and released for the main field after final testing. The survey took place from May to October 2018.

\section{Analysis}

Twelve-month PSP incidences including 95\% CIs are reported in terms of frequencies and distributions of ambulatory PSP types. The data refer either to the weighted participants or to their reported PSPs. The analyses were carried out with SPSS V.25 and cross-checked with the statistics package R V.3.5.2 (base package).

\section{Patient and public involvement}

Patients were not actively involved in the development of the research question but participated in guided interviews that were conducted to generate items for the survey instrument. Patients were also involved in the study to pretest the survey instrument and finally participated as interviewees. We presented the study results at the German Coalition for Patient Safety Conference 2019 where we explicitly invited patient representatives as discussants.

\section{RESULTS}

\section{Participants}

The survey participants ( $\mathrm{n}=10 \quad 037 ; 12.4 \%$ participation rate) were 61 years old on average, and 52\% were women. Seventy-three per cent assessed their current state of health as (very) good to mediocre; $47 \%$ stated that they had at least one long-lasting chronic disease at the time of the survey. Eight thousand eight hundred and forty-one of the 10037 participants $(88 \%)$ experienced at least one ambulatory GP or specialist visit within the past 12 months. Online supplementary table 1 compares the sociodemographic and socioeconomic parameters of the weighted study population with a population survey conducted as part of Germany's health monitoring 2014. The study population largely corresponds to the participants in the population survey.

\section{Incidence and medical treatment areas affected by PSPS}

The weighted sample comprises 8776 patients with an ambulatory GP or specialist visit, of whom $1422(16 \%)$ experienced at least one PSP in the last 12 months. They reported a total of 2589 PSPs, that is, an average of 1.8 PSPs per participant. In relation to the total sample, $14.2 \%$ experienced at least one PSP (1422/10 037). The most common areas affected by PSP were anamnesis/ diagnostic procedures (66\% of patients, $61 \%$ of PSPs) and medication (22\% of patients, $15 \%$ of PSPs). Table 1 shows the distribution of PSPs in all treatment areas including $95 \%$ CIs.

\section{PSP types}

Table 2 shows the distribution of the specifically surveyed PSP types per treatment area. In the two areas most frequently affected by PSPs (anamnesis/diagnostic procedures and medication), the most frequent PSP types are distributed as follows: $35 \%$ of all PSPs or 57\% of PSPs in the field of anamnesis/diagnostic procedures $(n=1583)$ are attributable to 'important questions about complaints not asked' as well as 'insufficient physical examination'. In the area of medication $(n=398,6.2 \%$ of all PSPs), $20.8 \%$ of medication-related PSPs were due to 'wrongly 
Table 1 Patients affected by PSP and distribution of PSPs by treatment areas

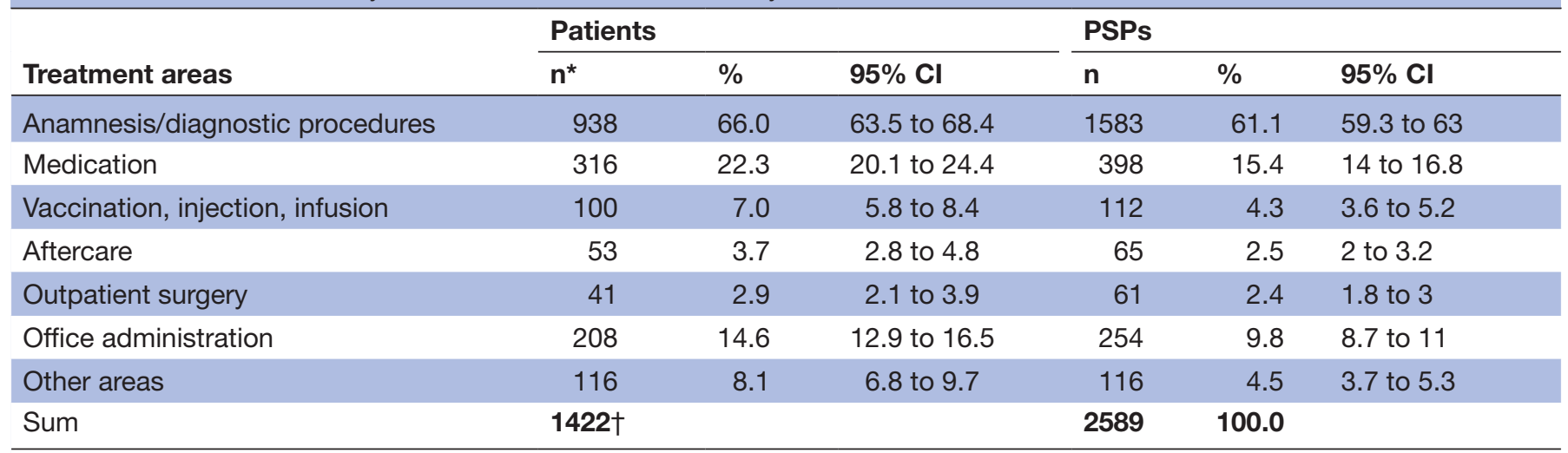

*Multiple answers possible; sample: 8776 weighted patients $\geq 40$ years with a doctor's visit within the last 12 months. †Individual patients, some affected by several PSPs.

PSP, patient safety problem.

prescribed drugs' and 'prescribed without considering the interaction with another drug' (19.7\%).

\section{Distribution of PSPs between specialist groups}

Of 2521 reported, clearly assignable PSPs, about $44 \%$ occurred among general practitioners, $15 \%$ among orthopaedists and $10 \%$ among internists. The other specialist groups received up to $5 \%$ of the PSP entries (online supplementary table 2 ).

\section{Types of harm, severity and time to recover}

One thousand nine hundred and thirty-five (74.7\%) of 2589 PSPs were associated with harm to the patient (table 3). A total of 5656 harms were reported, that is, an average of three harms per PSP. Two-thirds were described as harm to health, one third as financial/temporal/other harm. Due to the possibility of giving multiple answers, about $82 \%$ of PSPs were associated with at least one harm to health, $71 \%$ had at least one financial, temporal or other harm. Among the harms to health, "unnecessarily prolonged pain' was most frequently mentioned in $16.5 \%$ of all PSP harms and 'deterioration of the state of health' in $16.1 \%$ of all PSP harms.

Of the 1935 PSPs with at least one harm, $55.8 \%$ were rated as (very) severe. $35.3 \%$ of PSPs led to 'permanent harm' or required 'more than 1 month' of recovery (24.1\%). Eight hundred and four PSPs $(31.5 \%)$ prompted patients to see another doctor for additional treatment; 255 PSPs $(10 \%)$ required inpatient treatment overnight, with $2.4 \%$ requiring an inpatient stay of more than 2 weeks (table 4).

\section{Subanalysis of the most frequently reported PSP types}

Among the 2589 PSPs recorded, the PSP type 'important questions not asked about complaints' (a) was the most frequent with $515(19.9 \%)$ responses, followed by 'inadequate physical examination' (b) with 381 responses (14.7\%) (table 2). A subanalysis revealed 136 (a) and 107 (b) cases, in which participants had only experienced this one PSP type once in the last 12 months. 100 (a) and 70 (b) of these patients reported harmful consequences. These resulted in a deterioration of health status or persistent pain in 90 (a)/72 (b) cases, were (very) severe in 55 (a)/23 (b) cases, permanent in 34 (a)/24 (b) cases and resulted in 12 (a)/11 (b) hospital stays (online supplementary tables 3 and 4 ).

\section{DISCUSSION}

For the very first time, our study reports the frequency, types and consequences of PSPs in the ambulatory care sector in Germany, as measured by a representative sample of $\geq 40$-year-olds. It thus provides an important starting point for PSP prevention measures and improving patient safety. Within the last 12 months, 1422 out of 10037 respondents ( $14 \%$ of the population and $16 \%$ of those with a doctor's visit, respectively) had experienced a total of 2589 PSPs. Extrapolated to the total population at risk in Germany (47.2 million $\geq 40$ years), 12.2 million PSPs could be expected for 6.7 million patients $\geq 40$ years per year. Based on an average of 10-20 ambulatory doctor visits per year in this age group, $1.3 \%-2.6 \%$ of these visits might be associated with a PSP. According to the patients' reports, around 1.2 of the current 19.4 million inpatient cases $(6.2 \%)$ per year in Germany might be due to PSPs in ambulatory care, which are experienced by patients $\geq 40$ years alone. ${ }^{18}$ With an average case value of $3457 €$ in 2018 , these hospital stays cost around 4.15 billion $€ /$ year. As a matter of priority, the harm to patients resulting from PSPs must be avoided; additionally, the prevention of PSPs in ambulatory care would also be of huge economic importance.

According to our study, the PSP rate in Germany is in the lower range of the range of 1-24 PSIs per 100 consultations as reported by Panesar $e t a l,{ }^{8}$ undercuts the PSI rate of $21 \%{ }^{4}$ from the Netherlands, which was collected in a review of medical records, but is higher than the potentially harmful preventable problems rate of $7.9 \%^{5}$ for $\geq 15$-year-olds in Great Britain. Different recording methods, age groups and healthcare systems (eg, primary care systems without 
Table 2 Distribution of PSPs ( $n=2589)$ among specific PSP types in ambulatory care

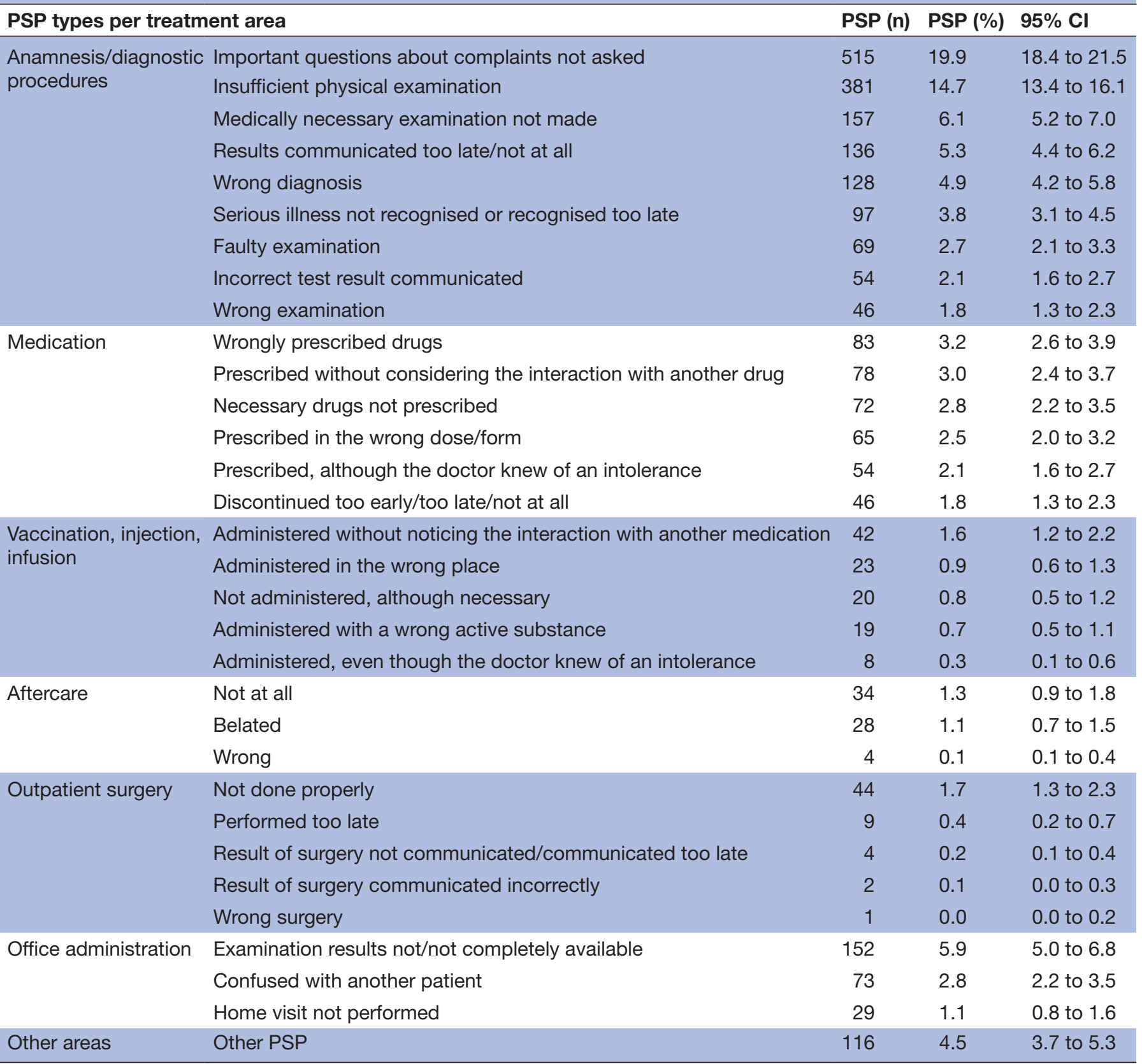

PSP, patient safety problem.

specialised physicians in private practices as is the case with Germany) must be considered, which makes international comparison difficult.

Considering only those PSPs associated with harm to health, the proportion of people who have experienced at least one harm to health in the past year due to a PSP in ambulatory care is $10 \%$ (889 out of 8776 participants visiting a doctor, data not reported here) and thus comparable to the upper estimate range of the inpatient sector, in which $5 \%-10 \%$ of cases experience an AE. ${ }^{3}$

With regard to the medical treatment areas most frequently affected by PSPs, it can be stated that the most frequent ambulatory diagnostic and therapeutic activities (anamnesis/diagnostic procedures, medication) are associated with most PSPs. Particularly medication is also repeatedly highlighted internationally as a frequent source of PSIs with harmful consequences in ambulatory care. ${ }^{8}$ Similarly, more PSPs occur in specialties with a higher number of visits (GPs and internists), with the exception of orthopaedists, who account for $14.5 \%$ of all PSPs, although they account for only $5 \%$ of all physicians in the ambulatory care sector in Germany. This phenomenon is also known from inpatient and ambulatory malpractice statistics. ${ }^{19}$ An astonishing result of our study is that patients most frequently name PSP types that doctors think are hardly likely to cause harm 


\begin{tabular}{|c|c|c|c|}
\hline PSP with harmful consequences & \multirow{2}{*}{$\frac{\text { PSP (n) }}{621}$} & \multirow{2}{*}{$\begin{array}{l}\text { PSP (\%) } \\
24.0\end{array}$} & \multirow{2}{*}{$\begin{array}{l}95 \% \mathrm{Cl} \\
22.4 \text { to } 25.7\end{array}$} \\
\hline PSP without harm & & & \\
\hline Refused to answer & 18 & 0.7 & 0.4 to 1.1 \\
\hline Don't know & 15 & 0.6 & 0.3 to 0.9 \\
\hline Deterioration of the health status & 909 & 16.1 & 15.1 to 17.1 \\
\hline Mental/social harm & 619 & 10.9 & 9.2 to 11.8 \\
\hline Serious illness not recognised/recognised too late & 306 & 5.4 & 4.9 to 5.7 \\
\hline Other part of the body injured (eg, an internal organ or nerve) & 228 & 4.0 & 3.4 to 4.6 \\
\hline Wound infection/inflammation & 223 & 3.9 & 3.3 to 4.5 \\
\hline Severe allergic reaction & 65 & 1.1 & 0.9 to 1.5 \\
\hline Total reported harms to health & 3758 & 66.4 & 65.2 to 67.7 \\
\hline PSP with $\geq 1$ harm to health & 1584 & 81.9 & 80.1 to 83.5 \\
\hline Temporal harm (eg, extra waiting time, additional doctor visits) & 1164 & 20.6 & 16.2 to 21.7 \\
\hline Financial harm (eg, additional treatment costs) & 393 & 6.9 & 6.3 to 7.1 \\
\hline Other harm & 341 & 6.0 & 5.4 to 6.7 \\
\hline Total reported financial, temporal and other harms & 1898 & 33.6 & 32.3 to 34.8 \\
\hline PSP with $\geq 1$ financial, temporal, other harm & 1378 & 71.2 & 69.2 to 73.2 \\
\hline
\end{tabular}

PSP, patient safety problem.

and sometimes doubt that patients are able to assess them correctly. This applies in particular to the most common PSP types from the area of anamnesis/diagnostic procedures, namely 'important questions not asked about the complaints' and 'insufficient physical examination', which together make up $35 \%$ of all PSP types. A possible explanation for this finding could be that many patients claim to have visited another doctor $(31.5 \%)$ or even a hospital $(10.0 \%)$ later and that during this visit it was explained that a certain question should have been asked or an examination carried out at the first contact. In addition, the subanalyses prove that even these supposedly harmless PSPs were the cause of permanent harm in about one third and led to inpatient treatment in 13.6\% of the cases from the perspective of those patients who had only reported this type of PSP.

With regard to the survey instrument, PSPs of the last 12 months should be reported, a period that is also used in the PREOS-PC (Patient Reported Experiences and Outcomes of Safety in Primary Care) survey. ${ }^{20}$ The short introductory text informs the patients that the interview focusses on PSPs that the participants themselves have experienced and perceived in the last 12 months as well as on those PSPs they learnt about later. Furthermore, complex filter guides were used in such a way that the target person was only asked the questions relevant to their specific situation. By this, both, the increased burden as well as the risk of memory bias were systematically reduced-however, as in other studies ${ }^{21}$ they cannot be avoided completely.

\section{Strengths and limitations of the study}

The main strength of the study lies in the fact that, for the first-time, PSP frequencies and distribution in the ambulatory care sector were collected in a representative, extensive population sample, so that a high degree of certainty is achieved in the PSP incidence estimates. Our study identifies that three-quarters of all PSPs reported by patients occur in the areas of anamnesis, diagnostic procedures and medication. It also provides insights into which PSPs are most likely to cause harm. Thus, the study provides a good indication of effective fields of action to improve patient safety. Our study also reveals that the majority of reported ambulatory PSPs leads to an additional use of the healthcare system, thus demonstrating that PSPs reported by patients are of great importance for the ambulatory healthcare system.

A limitation exists with regard to the interview participation rate of $12.4 \%$, which is in the lower range of the rates in telephone surveys in Germany. Nevertheless, the random selection of participants resulted in a sample that allows to generalise the results to the population of $\geq 40$-year-olds. Our selectivity analyses show that random selection alone achieved a good overall population 
Table 4 Differentiation of severity, recovery time and additional treatments of the severest harm per patient with at least one PSP

\begin{tabular}{|c|c|c|c|c|}
\hline \multicolumn{2}{|c|}{ Differentiation of the 'severest' harm $(n=1935)$} & \multirow{2}{*}{$\begin{array}{l}\mathbf{n} \\
139\end{array}$} & \multirow{2}{*}{$\begin{array}{l}\% \\
7.2\end{array}$} & \multirow{2}{*}{$\frac{95 \% \mathrm{Cl}}{6.1 \text { to } 8.4}$} \\
\hline Severity & Very mild & & & \\
\hline & Mild & 689 & 35.6 & 33.5 to 37.8 \\
\hline & Very severe & 287 & 14.8 & 13.3 to 16.5 \\
\hline & Don't know & 25 & 1.3 & 0.9 to 1.9 \\
\hline \multirow[t]{5}{*}{ Recovery period } & Less than a week & 294 & 16.9 & 15.2 to 18.7 \\
\hline & More than a week, but less than a month & 347 & 19.9 & 18.1 to 21.9 \\
\hline & More than a month & 419 & 24.1 & 22.1 to 26.1 \\
\hline & Permanent harm & 615 & 35.3 & 33.1 to 37.6 \\
\hline & Don't know & 37 & 2.1 & 1.5 to 2.9 \\
\hline \multirow{9}{*}{ Additional treatment* } & Medical on-call service / emergency service & 126 & 4.9 & 4.2 to 5.8 \\
\hline & Emergency room & 227 & 8.9 & 7.9 to 10.1 \\
\hline & Inpatient treatment (overnight) & 255 & 10.0 & 7.8 to 10.0 \\
\hline & Up to 1 week & 98 & 3.8 & 3.2 to 4.7 \\
\hline & Between 1 and 2 weeks & 96 & 3.8 & 3.1 to 4.6 \\
\hline & 2 weeks and more & 60 & 2.4 & 1.8 to 3.0 \\
\hline & Don't know & 1 & 0.0 & 0.0 to 0.2 \\
\hline & Rehabilitation & 206 & 8.1 & 7.1 to 9.2 \\
\hline & None of it & 927 & 36.3 & 34.5 to 38.2 \\
\hline
\end{tabular}

*Multiple answers possible for additional treatments.

PSP, patient safety problem.

representation with only minor deviations and that the survey participants represent the target population in all important variables. For example, the proportion of women in the study corresponds exactly to the population statistics. In addition, the comparison with the last population survey of the Robert Koch Institute, which is responsible for health monitoring in Germany, shows that-almost exactly as in our sample- $51.2 \%$ of $\geq 40$-year-olds in Germany describe themselves as chronically $\mathrm{ill}^{22}$ and $88 \%$ of the total population had at least one outpatient visit to the doctor in the last 12 months. ${ }^{23}$ A selection bias towards persons with a potentially higher PSP risk (eg, high utilisers, multimorbidity) cannot, however, be excluded with absolute certainty.

Another limitation may be seen in the research method used to generate data on PSP frequency and distribution in ambulatory care. Critics may question whether asking patients is suitable for generating valid statements about PSP frequency and distribution at all. This method deliberately considers only the patient's subjective perspective and does not use comparative data (eg, medical records of the participants) to objectify the reported PSPs medically. However, studies that did not use patient reports but other methods to measure the type and frequency of PSP and harm also have to deal with weaknesses. Studies using, for example, voluntary reports from physicians ${ }^{24-27}$ have been criticised as an unreliable source, as physicians report PSP and harm less often than they actually do occur. ${ }^{15}$ Even the analysis of medical records and error reporting systems cannot be regarded as the best solution. As impressively shown in the study by Weingart et al, only about half of the AEs validated by inpatient physicians were documented in the medical records. None of these were documented in the error reporting systems. ${ }^{28}$

\section{Recommendations for research and practice}

Despite these limitations, our study provides important insights into both the risk of PSPs and the importance of the patient as an actor in the identification and reporting of PSPs in ambulatory care. ${ }^{29}{ }^{30}$ Based on our own findings as well as those of Sharma et $a l,{ }^{31}$ who show in their review that patients and their relatives could report more 
frequently on patient safety issues such as chemotherapy toxicity and events such as suboptimal service quality and communication problems that have not been perceived or identified by service providers, we believe that patient reports should play a more important role in improving patient safety.

To this end, it will first of all be necessary to raise awareness of the existence of PSPs in ambulatory care, both among physicians and other medical professionals, but also among patients and policymakers. The publication and discussion of our study results can contribute to this. In the medical profession, patient safety in ambulatory care should be addressed more frequently within the framework of the quality circles already introduced for doctors in private practice. Quality circles are also suitable for analysing PSPs in open discussions and developing ways of preventing PSPs. They are also useful for reducing the previously widespread reluctance to recognise patient reports as a valid source for recording PSPs. In addition, CIRS for the ambulatory care sector could be supplemented by those items that have proven to be particularly significant in our study. In Germany, all medical institutions are obliged to participate in error reporting systems, but the participation rate has so far been extremely low. ${ }^{9}$ It is questionable to what extent mandatory active participation is conducive or rather leads to harming the intrinsic motivation of medical professionals. At the very least, one could consider to follow the English example, and, within the framework of the review of internal quality management, check whether an institution actually reports PSPs in CIRS. Considering the importance of anamnesis and clinical examination for the occurrence of PSPs, it would be appropriate to increase the appreciation of these basic activities in patient care. So far, technical examinations and procedures in the German healthcare system are much better remunerated than anamnesis and clinical examination. For this reason, typically only little time is spent, a cause for complain for many patients. In Germany, a change in the remuneration of ambulatory physicians is therefore recommended in order to take advantage of this approach to improve patient safety.

\section{CONCLUSIONS}

Our results show that in the ambulatory care sector in Germany, PSPs are frequently reported by patients and often lead to harm to health and additional ambulatory or inpatient treatment. The findings can help to identify critical medical care situations and to develop targeted measures to avoid PSPs. Furthermore, our study indicates that patient reports are a valuable and complementary source to identify PSPs and to improve patient safety as well as the quality of ambulatory care.

Acknowledgements We would like to thank the 10037 citizens who took part in the CATI survey. We thank Professor N. Timmesfeld, University of Bochum, for her statistical support in the study planning. We also thank Susann Südhof and Dr Helmut Schröder (infas—Institute of Applied Social Sciences, Bonn), who supervised the CATI survey and its development, and Claudia Mehl (PhilippsUniversität Marburg), who critically reviewed the survey instrument.

Contributors All authors had full access to all of the data (including statistical reports and tables) in the study and take responsibility for the integrity of the data and the accuracy of the data analysis. Study guarantor: MG, WdC. Study concept and design: MG, SK, JL, WdC. Analysis and interpretation of data: MG, SK, MS, A0, $\mathrm{JL}$, WdC. Drafting of the manuscript: MG, SK. Critical revision of the manuscript for important intellectual content: all authors. Statistical analysis: SK, MS. Study supervision: $M G$.

Funding The study received funding from the Innovation Committee of the Federal Joint Committee, Germany (grant number 01VSF16015).

Competing interests None declared.

Patient consent for publication Not required.

Ethics approval Ethical approval for the study was obtained through the Ethics Committee of the Philipps-Universität Marburg (AZ 179/17).

Provenance and peer review Not commissioned; externally peer reviewed.

Data availability statement Data are available upon reasonable request. Deidentified data will be made available after all ongoing analyses are completed. Requesters will be required to sign a letter of agreement detailing the mechanisms by which the data will be kept secure and access restricted to their study team. The agreements will also state the recipient will not share the data with anyone outside of their research team.

Open access This is an open access article distributed in accordance with the Creative Commons Attribution Non Commercial (CC BY-NC 4.0) license, which permits others to distribute, remix, adapt, build upon this work non-commercially, and license their derivative works on different terms, provided the original work is properly cited, appropriate credit is given, any changes made indicated, and the use is non-commercial. See: http://creativecommons.org/licenses/by-nc/4.0/.

ORCID iD

Max Geraedts http://orcid.org/0000-0002-5596-6246

\section{REFERENCES}

1 Institute of Medicine. Crossing the quality chasm: a new health system for the 21st century. Washington (DC): National Academies Press (US), 2001.

2 World Health Organization. The conceptual framework for the International classification for patient safety (ICPS). Geneva, 2009.

3 Sachverständigenrat zur Begutachtung der Entwicklung im Gesundheitswesen (SVR). Gutachten 2007 des SVR. Available: dipbt. bundestag.de/dip21/btd/16/063/1606339.pdf[Accessed 25 Jul 2019].

4 Gaal S, Verstappen W, Wolters R, et al. Prevalence and consequences of patient safety incidents in general practice in the Netherlands: a retrospective medical record review study. Implement Sci 2011;6:37.

5 Stocks SJ, Donnelly A, Esmail A, et al. Frequency and nature of potentially harmful preventable problems in primary care from the patient's perspective with clinician review: a population-level survey in Great Britain. BMJ Open 2018;8:e020952.

6 Michel P, Brami J, Chanelière M, et al. Patient safety incidents are common in primary care: a national prospective active incident reporting survey. PLoS One 2017;12:e0165455.

7 Sandars J, Esmail A. The frequency and nature of medical error in primary care: understanding the diversity across studies. Fam Pract 2003;20:231-6.

8 Panesar SS, deSilva D, Carson-Stevens A, et al. How safe is primary care? A systematic review. BMJ Qual Saf 2016;25:544-53.

9 Jeder-Fehler-Zählt: Fehler-Datenbank. Available: www.jeder-fehlerzaehlt.de/public/report/databaseNewest.jsp [Accessed 25 Jul 2019].

10 World Health Organization. Patient safety curriculum guide. Multiprofessional edition. who library Cataloguing-in-Publication data, 2011. Available: apps.who.int/iris/bitstream/handle/10665/44641/ 9789241501958_eng.pdf?sequence=1 [Accessed 25 Jul 2019].

11 Agency for Healthcare Research and Quality. Designing consumer reporting systems for patient safety events. Available: www.ahrq. gov/professionals/quality-patient-safety/patient-safety-resources/ resources/consumer-experience/reporting/index.html [Accessed 29 Apr 2016].

12 Lang S, Garrido MV, Heintze C. Patients' views of adverse events in primary and ambulatory care: a systematic review to assess methods 
and the content of what patients consider to be adverse events. BMC Fam Pract 2016;17:6.

13 Vincent CA, Coulter A. Patient safety: what about the patient? Qual Saf Health Care 2002;11:76-80.

14 Ward JK, Armitage G. Can patients report patient safety incidents in a hospital setting? A systematic review. BMJ Qual Saf 2012;21:685-99.

15 Rea D, Griffiths S. Patient safety in primary care: incident reporting and significant event reviews in British general practice. Health Soc Care Community 2016;24:411-9.

16 STROBE Statement-Checklist of items that should be included in reports of cross-sectional studies. Available: https://www.strobestatement.org/fileadmin/Strobe/uploads/checklists/STROBE checklist_v4_cross-sectional.pdf [Accessed 11 Dec 2019].

17 Lenzner T, Neuert C, Otto W. GESIS survey guidelines - Kognitives Pretesting. Available: www.gesis.org/fileadmin/upload/SDMwiki/ Kognitives_Pretesting_Lenzner_Neuert_Otto_08102015_1.1.pdf [Accessed 25 Jul 2019].

18 Statistisches Bundesamt. Grunddaten der Krankenhäuser. Fachserie 12 Reihe 6.1.1, 2018. Available: https://www.destatis.de/DE/Themen/ Gesellschaft-Umwelt/Gesundheit/Krankenhaeuser/_inhalt.html\# sprg234206 [Accessed 13 Dec 2019].

19 Osterloh F. Qualitätssicherung: Ärzte machen wenig Fehler. Dtsch Arzteb/ 2019;116:A-718.

20 Ricci-Cabello I, Avery AJ, Reeves D, et al. Measuring Patient Safety in Primary Care: The Development and Validation of the "Patient Reported Experiences and Outcomes of Safety in Primary Care" (PREOS-PC). Ann Fam Med 2016;14:253-61.

21 Gehring K, Schwappach DLB, Battaglia M, et al. Frequency of and harm associated with primary care safety incidents. Am J Manag Care 2012;18:e323-37.

22 Robert-Koch-Institut. Beitrag zur Gesundheitsberichterstattung des Bundes - GEDA12. Available: https://www.rki.de/DE/Content/Gesu
ndheitsmonitoring/Gesundheitsberichterstattung/GBEDownloadsB/ GEDA12.pdf;jsessionid=F270871E50518320B36CA4ABA58DF80E. 1_cid290?_blob=publicationFile [Accessed 10 Dec 2019].

23 Prütz F, Rommel A. Inanspruchnahme ambulanter ärztlicher Versorgung in Deutschland. Journal of Health Monitoring 2017;2:88-94.

24 Dovey SMet al. A preliminary taxonomy of medical errors in family practice. Qual Saf Health Care 2002;11:233-8.

25 Elder NC, Vonder Meulen MB, Cassedy A. The identification of medical errors by family physicians during outpatient visits. Ann Fam Med 2004;2:125-9.

26 Rosser W, Dovey S, Bordman R, et al. Medical errors in primary care: results of an international study of family practice. Can Fam Physician 2005;51:386-7.

27 Makeham MAB, County M, Kidd MR, et al. An international taxonomy for errors in general practice: a pilot study. Med J Aust 2002;177:68-72.

28 Weingart SN, Pagovich O, Sands DZ, et al. What can hospitalized patients tell us about adverse events? Learning from patient-reported incidents. J Gen Intern Med 2005;20:830-6.

29 Unruh KT, Pratt W. Patients as actors: the patient's role in detecting, preventing, and recovering from medical errors. Int $J$ Med Inform 2007;76:S236-44.

30 Lawton R, O'Hara JK, Sheard L, et al. Can staff and patient perspectives on hospital safety predict harm-free care? an analysis of staff and patient survey data and routinely collected outcomes. BMJ Qual Saf 2015;24:369-76.

31 Sharma AE, Rivadeneira NA, Barr-Walker J, et al. Patient engagement in health care safety: an overview of mixed-quality evidence. Health Aff 2018;37:1813-20. 